\title{
Are we there yet? Use of the Ottawa Charter action areas in the perspective of European health promotion professionals
}

\author{
Angelika Wilberg $^{1} \cdot$ Luis Saboga-Nunes ${ }^{2} \cdot$ Christiane Stock $^{3,4}$ (i)
}

Received: 4 April 2019 / Accepted: 17 June 2019 / Published online: 4 July 2019

(C) The Author(s) 2019

\section{Introduction}

The Ottawa Charter for Health Promotion, sub-titled "The Move Towards a New Public Health," has been identified as an influential and guiding document and tool (IUHPE and CCHPR 2008; Baum and Sanders 2011) responsible for laying a foundation for health promotion theory and practice (IUHPE and CCHPR 2008; Nutbeam 2008) and broadening its outcomes beyond the absence of disease (Laverack and Mohammadi 2011). Since its inception at the First International WHO Conference on Health promotion in Ottawa, Canada, in November 1986, it has sparked the conceptualization, development, discourse, and integration of health promotion while inspiring professionals, politicians, and citizens worldwide (Dooris 2013), giving health promoters a sense of identity (Pettersson 2011) and taking on a 'Holy Grail' status (McPhail-Bell, Fredericks and Brough 2013).

The Charter provided a strong, holistic vision highlighting interdependency (Porter 2007) while describing health as a resource for everyday living and health promotion as "the process of enabling people to increase control over, and to improve, their health" (Ottawa Charter for Health Promotion 1986). The Charter also paved the way for the settings approach to health promotion (Dooris 2013) and an "active and interactive" comprehension of health (Kickbusch 2007).

Christiane Stock

christiane.stock@charite.de

1 Faculty of Life Sciences, Hamburg University of Applied Sciences, Hamburg, Germany

2 Universidade NOVA de Lisboa-National School of Public Health, Lisbon, Portugal

3 Institute for Health and Nursing Science, Charité Universitätsmedizin, Augustenburger Platz 1, 13353 Berlin, Germany

4 Unit for Health Promotion Research, University of Southern Denmark, Odense, Denmark
Health promoters were presented with various roles and functions which were delineated in the Charter (advocating, enabling, and mediating) and recommended five action areas, which at the time of publication were awaited but also considered quite radical (Scriven and Speller 2007). Areas considered essential for public health action (Kickbusch 2007) included: healthy public policies, supportive environments, personal skills, community action, and reorientation of health services. Building healthy public policy involves advocating for and establishing health as political priorities at all levels and sectors, embracing accountability for health and decision-making impacts on health (WHO 2009; Ottawa Conference Report 1986). The action area "Creating supportive environments" acknowledges the interconnectedness between people and their environment and that people, communities, and the environment need to be cared for and protected with unified, mutual action (WHO 2009; Ottawa Conference Report 1986b). Strengthening community action puts a focus on engaging community resources and strengthening competencies, collaboration, and participation (WHO 2009; Ottawa Conference Report 1986c; Fry and Zask 2016). Developing personal skills is often referred to as health education and health literacy (Fry and Zask 2016). The supplementations of health information and skill development are ways health promoters can care for the personal and social growth of individuals and provide options to foster greater choice and control within environments and towards maintenance of health and wellbeing (WHO 2009; Ottawa Conference Report 1986d; Fry and Zask, 2016). Reorienting health services advocates for a health care system which prioritizes health and requires the shared responsibility and contributions of people, communities, health professionals, organizations, and government (WHO 2009; Ottawa Conference Report 1986e).

The purpose of health promotion was to combine the old public health with a commitment to the new public health, thus creating a synergy between a social determinants approach and individual and community empowerment 
(Kickbusch 2007). Ottawa's vision focused on establishing the norm of partnerships between multiple sectors, upstream measures (addressing fundamental influences on poor health and injustices) (Bharmal, Devose, Felician and Weden 2015), and the engagement and participation of individuals and communities in decisions about their health and wellbeing (Scriven and Speller 2007).

The discourse around the Ottawa Charter and health promotion still continues to circulate within public health and beyond. The challenges and new obstacles that have arisen since Ottawa have prompted initiation of the "Vienna Declaration" launched by the European Public Health Association (EUPHA), which strives to renew the dedication to the principles of the Ottawa Charter for Health promotion by reviewing, updating, and expanding on the prerequisites of health, functions, and action areas (EUPHA 2016). In this context exploring the opinions of health professionals working within health promotion is well warranted. The purpose of this study is to assess the relevance and use of the Ottawa Charter for health promotion today from the perspective of health professionals who are members of the health promotion section within the European Public Health Association (EUPHA). Within EUPHA, public health and health promotion professionals are organized who are typically researchers, health promotion/public health practitioners, or employed in the public health administration, or they work in teaching and education in this field. The main aims of the study were to explore the opinions of such EUPHA-associated health promotion professionals regarding how the Charter and health promotion concepts and practices have been applied in Europe and how the recognition of the field of health promotion is perceived.

\section{Methods}

\section{Data collection}

The questionnaire study was conducted between April and May 2016. An invitation to participate was sent out to all individuals enrolled as members of the health promotion section of the European Public Health Association, EUPHA $(N=2400)$, in April 2016. A second invitation was sent in May 2016 to all section members to increase participation. Answers were collected from 198 participants, and data from 193 respondents (response rate $8 \%$ ) were included in the analysis. Characteristics of the respondents are represented in Table 1.

\section{Survey design}

The survey questions were developed by the authors on behalf of the EUPHA section health promotion. A pilot test of the questionnaire was executed in March 2016 among 20 health promotion researchers and practitioners to reflect relevant
Table 1 Characteristics of the sample (in valid percentages)

\begin{tabular}{|c|c|c|}
\hline & $\mathrm{N}$ & $\%$ \\
\hline \multicolumn{3}{|l|}{ Age: } \\
\hline$<25$ years & 3 & $1.6 \%$ \\
\hline 25-34 years & 35 & $18.1 \%$ \\
\hline $35-44$ years & 38 & $19.7 \%$ \\
\hline $45-54$ years & 56 & $29.0 \%$ \\
\hline $55-64$ years & 46 & $23.8 \%$ \\
\hline$>65$ years & 15 & $7.8 \%$ \\
\hline \multicolumn{3}{|l|}{ Gender: } \\
\hline Female & 128 & $67.0 \%$ \\
\hline Male & 63 & $33.0 \%$ \\
\hline \multicolumn{3}{|l|}{ Global region: } \\
\hline Southern European & 54 & $29.5 \%$ \\
\hline Western European & 47 & $25.7 \%$ \\
\hline Northern European & 45 & $24.6 \%$ \\
\hline Eastern European & 19 & $10.4 \%$ \\
\hline Other & 18 & $9.8 \%$ \\
\hline \multicolumn{3}{|l|}{ Professional domain: } \\
\hline Curative/palliative/health care worker & 19 & $9.8 \%$ \\
\hline $\begin{array}{l}\text { Health promotion/public health } \\
\text { practitioner/public health administration }\end{array}$ & 72 & $37.2 \%$ \\
\hline Researcher and/or teaching/education & 102 & $52.8 \%$ \\
\hline \multicolumn{3}{|c|}{ Length of time working in public health/health promotion: } \\
\hline$<5$ years & 29 & $15.0 \%$ \\
\hline $5-15$ years & 66 & $34.2 \%$ \\
\hline $16-30$ years & 75 & $38.9 \%$ \\
\hline$>30$ years & 23 & $11.9 \%$ \\
\hline
\end{tabular}

feedback. The participants were asked questions related to socio-demographics and professional characteristics including age and gender, one's country of reference for their work as a health professional, and the number of years working in the field of health promotion/public health. The participants were asked what type of professional domain they identify with, and the three answering options were: researcher, health promotion/public health practitioner or public health administration, and teaching/education. For the analysis, the categories "Researcher" and "Teaching/education" were collapsed into "Researcher and/or teaching/education". Reference countries were then divided into six global regions according to WHO while European countries were divided into Northern, Southern, Eastern, and Western Europe according to the United Nation's geoscheme for Europe (https://unstats.un. org/unsd/methodology/m49/). A total of 18 respondents were from countries outside of Europe, namely Australia (1), Brasil (1), Canada (4), Egypt (1), Indonesia (1), Israel (6), Nigeria (2), and Taiwan (2). Participants were asked to reflect on their perceived progress in health promotion since the Ottawa Charter's development 30 years ago and to state the level to which they agreed or disagreed with various 
statements. The content of statements is shown in Table 2, and five category options were provided to identify with the statements: "strongly agree," "agree," "unsure," "disagree," and "strongly disagree." For the analysis, "strongly agree" and "agree" were collapsed into one category, "unsure" was independent, while "strongly disagree" and "disagree" were collapsed into another category resulting in a total of three categories.

Perceived use of the Ottawa Charter action areas in the respondents' respective country was evaluated with a series of questions. Respondents were asked to reflect on the five action areas of the Ottawa Charter (developing healthy public policy, creating supportive environments, strengthening community action, developing personal skills and knowledge, reorientation of health services). For each action area, a rank of five options was presented to respondents to categorize perceived use: I do not know, never used, sometimes used, used regularly, and used very often. Further analysis collapsed "used regularly" and "used very often" into one category.

\section{Ethics and confidentiality}

All participants were informed that participation was voluntary and that the data were collected pseudo-anonymously and treated confidentially. Data of participants were treated according to the data protection legislation.

\section{Statistical methods}

Descriptive statistics were conducted in STATA 14.0. Chisquare tests were conducted to determine the measures of association between certain variables such as global region and professional domain with perceived applicability of each of the five actions areas.

\section{Results}

\section{Characteristics of the respondents}

The majority of respondents $(90.6 \%)$ were in the age of working life between 25 years and 64 years, and $85.0 \%$ have $\geq 5$ years of work experience in the field of public health/health promotion. Two thirds of respondents were females (67.0\%). While respondents from Northern, Western, and Southern European regions were fairly evenly represented, only $10.7 \%$ of respondents were from Eastern European countries and 9.8\% from outside of Europe. Most of the respondents identified themselves as belonging to the category "researcher and/or teaching/education" (52.3\%) followed by "practitioners/administration" (37.2\%), while only $9.8 \%$ identified themselves as "curative/palliative/health care worker" (Table 1).

\section{Perceived progress of health promotion}

As shown in Table $243.7 \%$ of respondents agreed that the field of health promotion is well established in their country. When asked whether they felt that health promotion was well established in Europe, $50.0 \%$ agreed. Although $80.0 \%$ of survey participants felt that the topic of health promotion has progressed over the past 30 years, $80.7 \%$ also felt that the topic of health promotion is in need of a deeper reflection since the development of the Ottawa Charter.

\section{Frequency of use of the action areas}

When participants were asked to rate the perceived use of the five Ottawa Charter action areas in their reference country, the percentage of use was rated highest for "Developing personal skills and knowledge" at $63.2 \%$ followed by "Developing healthy public policy" at $44.8 \%$, with the rate slightly dropping for "Strengthening community action" at $40.7 \%$, declining to $37.0 \%$ for "Creating supportive environments" and lowest for "Reorientation of health services" with $30.5 \%$ (Table 3).

The use of the five action areas was generally rated highest among Northern European participants and among those from outside Europe (others) and lowest among Eastern and Southern European participants. The difference in ratings between countries was only significant for "Strengthening community action" and "Creating supportive environments," where only about $10 \%$ of the participants from Eastern European countries stated use of the action in their reference countries, while this was the case for at least $28 \%$ of respondents from the other regions (Table 3).

Table 2 Perceived progress of health promotion among survey respondents $(N=193)$

\begin{tabular}{|c|c|c|c|}
\hline Statements & Agree $(\%)$ & Disagree $(\%)$ & Unsure $(\%)$ \\
\hline $\begin{array}{l}\text { Since the development of the Ottawa Charter in 1986, the field of health promotion is well e } \\
\text { stablished in my country }\end{array}$ & 43.7 & 30.0 & 26.3 \\
\hline After 30 years of the Ottawa Charter, the field of health promotion is well established in Europe & 50.0 & 17.9 & 32.1 \\
\hline Overall knowledge about the topic of health promotion has progressed over the past 30 years & 80.0 & 9.5 & 10.5 \\
\hline The topic of health promotion requires deeper reflection since the development of the Ottawa Charter & 80.7 & 5.7 & 13.5 \\
\hline
\end{tabular}


Table 3 Frequency of perceived use of Ottawa Charter action areas in their respective countries (in valid percent) in total and by region and professional domain

\begin{tabular}{|c|c|c|c|c|c|c|c|c|c|c|}
\hline \multirow[t]{2}{*}{ Global region } & \multicolumn{2}{|c|}{$\begin{array}{l}\text { Healthy } \\
\text { public policy }\end{array}$} & \multicolumn{2}{|c|}{$\begin{array}{l}\text { Supportive } \\
\text { environments }\end{array}$} & \multicolumn{2}{|c|}{$\begin{array}{l}\text { Strengthening } \\
\text { community action }\end{array}$} & \multicolumn{2}{|c|}{$\begin{array}{l}\text { Developing } \\
\text { personal skills }\end{array}$} & \multicolumn{2}{|c|}{$\begin{array}{l}\text { Reorientation of } \\
\text { health services }\end{array}$} \\
\hline & $\mathrm{N}$ & $\%$ & $\mathrm{~N}$ & $\%$ & $\mathrm{~N}$ & $\%$ & $\mathrm{~N}$ & $\%$ & $\mathrm{~N}$ & $\%$ \\
\hline $\begin{array}{l}\text { Total } \\
N=182 \\
\text { Geographical regions }\end{array}$ & 82 & 44.8 & 67 & 37.0 & 74 & 40.7 & 115 & 63.2 & 56 & 30.3 \\
\hline $\begin{array}{l}\text { Southern European } \\
N=54\end{array}$ & 24 & 44.4 & 15 & 28.3 & 17 & 31.5 & 27 & 50.0 & 14 & 25.9 \\
\hline $\begin{array}{l}\text { Western European } \\
N=47\end{array}$ & 17 & 36.2 & 18 & 38.3 & 20 & 42.6 & 35 & 74.5 & 16 & 34.0 \\
\hline $\begin{array}{l}\text { Northern European } \\
N=45\end{array}$ & 24 & 53.3 & 22 & 48.9 & 24 & 53.3 & 32 & 71.1 & 16 & 35.6 \\
\hline $\begin{array}{l}\text { Eastern European } \\
\mathrm{N}=19\end{array}$ & 8 & 42.1 & 2 & 10.5 & 2 & 10.5 & 10 & 52.6 & 4 & 21.1 \\
\hline $\begin{array}{l}\quad \text { Other } \\
N=17 \\
\text { Professional domain }\end{array}$ & 9 & 50.0 & 10 & 58.8 & 11 & 64.7 & 11 & 64.7 & 6 & 35.3 \\
\hline Curative/palliative/ health care worker $N=19$ & 10 & 52.6 & 6 & 31.6 & 9 & 47.4 & 9 & 47.4 & 4 & 21.1 \\
\hline Practitioner/public health administration $N=70$ & 26 & 36.6 & 23 & 32.9 & 27 & 38.6 & 45 & 64.3 & 21 & 30.0 \\
\hline Researcher and/or teaching/education $N=101$ & 49 & 48.0 & 42 & 41.6 & 42 & 41.6 & 67 & 66.3 & 33 & 32.7 \\
\hline$P$ value (chi ${ }^{2}$ test between professions) & 0.24 & & 0.439 & & 0.7 & & 0.286 & & 0.59 & \\
\hline$P$ value (chi ${ }^{2}$ test between regions) & 0.55 & & 0.008 & & 0.00 & & 0.068 & & 0.67 & \\
\hline
\end{tabular}

The perceived use of the five actions areas in their respective countries did not significantly differ by professional domain. Rather the frequencies reflect a relatively high use of strategies to develop personal skills and a low perceived implementation of reorientation of the health system (Table 3 ).

\section{Discussion}

This study investigated how the Ottawa Charter and health promotion concepts and principles have been applied across European regions and professional domains in the perspective of health promotion professionals. Regarding the perceived use of action areas in the health promotion field, "Developing personal skills and knowledge" (64\%) was rated most frequently and regularly used in one's country among participants, the highest among Western (75\%) and Northern Europeans $(71 \%)$ and lowest for Eastern $(53 \%)$ and Southern Europeans $(50 \%)$. The relatively high perceived use of educational strategies may be explained by the fact that this action area is relatively broad in potential impact with its core ideas as supplementing information, health education, and the enhancement of life skills (Ottawa Charter for Health Promotion 1986), which include many possibilities for usage. As McQueen and De Salazar (2011) explain, information can be an inactive concept, education is about broadening one's knowledge, and skills are a means that allow an individual to undertake certain actions. As a result, developing personal skills can include a wide range of initiatives. Furthermore, as pointed out by Weare et al. (1992), before the Ottawa Charter health education had already gained ground in various countries, particularly in the school setting. Therefore, existing methods, examples, and channels were likely available and easier to apply than some of the other action areas.

Though sharing health information and education has been shown to be an area with a fair amount of use in all geographic regions, the Vienna Declaration (2016) describes the current challenge is now the overload of information as well as misinformation that is now quickly accessed by citizens (EUPHA 2016). Managing this will require creative strategies from health promoters and the public health community as well as gaining the trust and respect of the public to continue sharing and disseminating credible knowledge and skills. It is somewhat a paradox that the Ottawa Charter was created initially in response to a heavy focus on individual approaches (Thompson et al. 2017) and that - as our data indicateafter 30 years the area "Development of personal skills" still seems to play the predominant role. One potential reason for this lack of a substantial shift in focus of health promotion action towards more upstream measures which was warranted by the Ottawa Charter might be the tendency within societies with mostly neo-liberal governments to withdraw from welfare in the 1990s, which has resulted in prioritizing more individualistic lifestyle approaches (Wills and Douglas 2008).

However, it might be attributed to the Ottawa Charter and its influence in the respective countries that as second-most 
common, "Developing healthy public policy" was declared as used by $44 \%$ of respondents with the highest percentage among Northern Europeans (53\%) and the lowest among Western Europeans (36\%), although the differences between regions were not significant. In agreement with our results, others state that over the past 30 years, more attention has been given to this domain in recent years and that stakeholders interested in health are increasing (Kickbusch 2010). Although there have been good examples of policies that aim at risk factors and disease reduction, there is also concern that comprehensive national policies that integrate actions to improve health and social and economic conditions across sectors are still rarely seen (IUHPE and CCHPR 2008).

As the next most common area, $41 \%$ of participants rated "Strengthening community action" as often used, with significant differences between regions showing the highest ratings for Northern Europeans (53\%) and the least for Eastern Europeans (11\%). The struggle in using this domain can be in part due to its complexity, which may focus on a different purpose or require engagement in various stages at different times such as participation, or becoming concerned with building on competencies and capacities, and is directed toward specific goals and actions (Laverack and Mohammadi 2011). At another stage, strengthening community action may be assisting communities to solve issues related to their lack of power and locating or using their voice to be more politically active. This has been considered to be the catalyst for empowerment (Laverack and Mohammadi 2011), a term which, though explored in this domain, is often elusive with its absence of concrete methodologies and strong evidence in diverse settings and cultural environments (Laverack and Wallerstein 2001). Furthermore, it is possible that its reliance on reorientation of health services and professional practice as well as the political climate that influences practitioners, communities, approaches, and agendas (Laverack and Mohammadi 2011) can further complicate the use and feasibility of this action area.

Next, only $36.3 \%$ of survey participants perceived "Creating supportive environments" to be often used with significant difference between regions with again the highest ratings among Northern Europeans (49\%), followed by Western (38\%) and Southern Europeans (28\%) and 11\% among Eastern Europeans. The relatively low use of this action area is in contrast to the IUHPE and CCHPR (2008) stating that settings-based initiatives should be cultivated as healthpromoting workplaces and schools tackle health determinants and behaviors. It is evident that in Europe and beyond, since the Ottawa Charter a plethora of international and national programs and networks have emerged, covering settings as diverse as regions, districts, cities, islands, schools, hospitals, workplaces, prisons, universities, and marketplaces (Dooris 2006). This can be considered major progress, but the influence is not as strong as it could have been according to Dooris (2006), and concerns exist about whether a consequence of a settings approach may at times result in fragmentation as settings operate at different levels (Dooris 2006).

Only $31 \%$ of survey respondents felt the action area "Reorientation of health services" was often used and $10 \%$ perceived it to never be used at all, without any significant differences between regions. This is not surprising as merging health promotion to the mainstream requires the investment, value, and collaboration of various stakeholders at local, regional, and global levels (Ziglio, Simpson and Tsouros 2011). Wise and Nutbeam (2007) assert that this action area has had minimal systematic attention as its own action area and with respect to the four other action areas and is still an unaccomplished agenda. Ziglio et al. (2011) state that part of this requires the reframing of messages. Also, Johannson and co-authors (2010) observed that though there may be willingness among health professionals in their Swedish sample to engage in more health promotion and disease prevention in primary care and hospital settings, several barriers such as high workload have made this challenging.

This study did not find any particular difference in ratings between respondents working in curative or practice settings compared with those in public health administration or in research, but differences according to European regions emerged. With the exception of "Developing personal skills", the perceived use of action areas in one's geographical region was in the order of Northern Europe, Western Europe, Southern Europe, and Eastern Europe, with "Community action" and "Supportive environments" being particularly low for Eastern Europeans. Though no conclusions can be drawn in this descriptive study, this pattern may give insight to the state of health promotion and public health progress and practice in these regions. Responses from a survey studying differences in public health research among Northern, Southern, and Eastern Europe indicated that health services, health promotion, prevention, and education were indeed priorities at a national level in countries identified as Northern and Western Europe in our study (Mannoci, Ricciardi and La Torre 2009), but infrastructures and technology shortages were identified barriers in Southern and Eastern Europe compared with the North (Mannoci et al. 2009).

Though the action areas are looked at individually in our study, one must keep in mind that they are designed to interconnect, which may impact their separate and overall use. However, as Ziglio et al. (2000) point out, most health promotion activity has continued to be issue-based or else has focused on only one determinant at a time. Therefore, health promoters should also be conscious of designing interventions to actively target more than one action area at a time, recognizing and demonstrating that each domain is mutually dependent on another, and achieving a major impact on the determinants of health or policy development (Ziglio et al. 2000).

A total of $72 \%$ of participants felt that health promotion sparks interest and engagement among health professionals 
and policy makers. This is a promising result as increased value for health promotion among stakeholders and the public is necessary to increase its demand. Such a demand is relevant in order to avoid that health promotion occurs infrequently rather than an essential service (Johannson et al. 2010). Also promising is the results that $72.5 \%$ of respondents felt that health promotion is a necessary field, and $80 \%$ agreed that overall knowledge about the topic of health promotion has progressed over the past 30 years. This is in line with the findings from Ziglio et al. (2000) who state that the implementation of a wide range of health promotion initiatives has generated much collective experience within Europe and added considerably to both knowledge and progressive change.

On the other hand, less than half $(44 \%)$ of the participants felt that the field of health promotion was well established in their country, and only $50 \%$ felt that it is currently well established in Europe. Though there have been well-known health promotion innovations in the European region since the Ottawa Charter, with the Investment for Health Approach, Healthy Cities, Health-Promoting Hospitals, and HealthPromoting Schools, to name a few, in agreement with our results, there is evidence that the overall impact of these innovations has been relatively limited in the region (Ziglio et al. 2000). It has been argued that the various social, political, and economic changes unfolding in European society parallel to the growth of health promotion have limited the impact of health promotion in different settings (Ziglio et al. 2000).

This study has limitations, as it only captures subjective perspectives regarding the relevance and use of the Ottawa Charter action areas but is unable to measure implementation in the European region. Other research aiming at quantifying implemented programs and actions in the different areas for European countries would be needed for this. Though this study indicates its focus on the European region and surveyed professionals connected to EUPHA, voices and perspectives of other countries are not captured, particularly in developing regions. The limited number of respondents $(n=18)$ from countries outside of Europe does not cover other relevant geographical areas. Therefore, the study widely excludes valuable perspectives on how useful or relevant the Charter has been outside of Europe. Furthermore, it excludes perspectives of those who are not yet experts or professionals, such as students or lay people. In addition, since only $8 \%$ of the health promotion section members responded to the survey invitation, the responses do not necessarily represent all section members. Furthermore, due to the limited sample size of respondents from some geographical regions, especially of those from Eastern European countries, the results regarding geographical variation need to be interpreted with caution. In the spirit of democracy, future reflections on the Ottawa Charter should seek to explore perspectives of the Ottawa Charter and its relevance from professionals outside of Europe and in developing regions as well as among non- experts. The Charter is a powerful document which should not only circulate and be analyzed within the public health community.

Though the Charter sparks motivation and hope, particularly at its conferences, a Charter with misplaced action, agreement upon, and advocacy for its principles will simply remain a Charter. Though progress has been made over 30 years, the unfulfilled potential coupled with emerging health threats may help to explain why $81 \%$ of participants in this study felt that the topic of health promotion requires deeper reflection since the development of the Ottawa Charter. It is undeniable that over the past 30 years global changes and challenges have emerged that require updated strategies to address new threats such as commercial determinants of health and noncommunicable diseases, to name a few. However, as Thompson and others (2017) point out, the Charter was created in response to a heavy focus on individual approaches, which is recently a returning problem along with other challenges such as access to water or health for all, for example. The Ottawa Charter continues to be a relevant concept as its vision highlights relevant issues that have yet to be resolved and presents roles for health promoters yet to be fulfilled and action areas yet to be optimally implemented.

Funding This research did not receive any particular funding.

\section{Compliance with ethical standards}

Conflict of interest The authors declare that they have no conflict of interest.

Open Access This article is distributed under the terms of the Creative Commons Attribution 4.0 International License (http:// creativecommons.org/licenses/by/4.0/), which permits unrestricted use, distribution, and reproduction in any medium, provided you give appropriate credit to the original author(s) and the source, provide a link to the Creative Commons license, and indicate if changes were made.

\section{References}

Baum FE, Sanders DM (2011) Ottawa 25 years on: a more radical agenda for health equity is still required. Health Promot Int 26(2):253-257. https://doi.org/10.1093/heapro/dar078

Bharmal N, Devose KP, Felician M, Weden MM (2015) Working paper: understanding the upstream social determinants of health. RAND Corporation, Santa Monica

Dooris M (2006) Health promoting settings: future directions. Promot Educ 13(1):2-4. https://doi.org/10.1177/10253823060130010101

Dooris M (2013) Expert voices for change: bridging the silos- towards healthy and sustainable settings for the 21 st century. Health Place 20:39-50. https://doi.org/10.1016/j.healthplace.2012.11.009

Fry D, Zask A (2016) Applying the Ottawa Charter to inform health promotion programme design. Health Promot Int 32(5):901-912. https://doi.org/10.1093/heapro/daw022

International Union of Health Promotion and Education (IUHPE) and Canadian Centre for Health Promotion Research (CCHPR) (2008) 
Shaping the future of health promotion: priorities for action. Health Promot Int 23(1):98-102

Johannson H, Stenlund H, Lundstrom L, Weinehall L (2010) Reorientation to more health promotion in health services - a study of barriers and possibilities from the perspective of health professionals. J Multidiscip Healthc 3:213-224. https://doi.org/10.2147/ JMDH.S14900

Kickbusch I (2007) The move towards a new public health. Promot Educ 9(2):40-41

Kickbusch I (2010) Health in all policies: where to from here? Health Promot Int 25(3):261-264. https://doi.org/10.1093/heapro/daq055

Laverack G, Keshavarz Mohammadi N (2011) What remains for the future: strengthening community actions to become an integral part of health promotion practice. Health Promot Int 26(2):258-262. https://doi.org/10.1093/heapro/dar068

Laverack G, Wallerstein N (2001) Measuring community empowerment: a fresh look at organizational domains. Health Promot Int 16(2): 179-185

Mannocci A, Ricciardi W, La Torre G (2009) Public-health research: are there differences between northern, southern and eastern european countries? A perspective from national public health associations. Ital J Publ Health 6(1):88-92

McPhail-Bell K, Fredericks B, Brough M (2013) Beyond the accolades: a postcolonial critique of the foundations of the Ottawa Charter. Glob Health Promot 20(2):22-29. https://doi.org/10.1177/ 1757975913490427

McQueen DV, De Salazar L (2011) Health promotion, the Ottawa Charter and 'developing personal skills': a compact history of 25 years. Health Promot Int 26(2):194-201. https://doi.org/10.1093/heapro/ dar063

Nutbeam D (2008) What would the Ottawa Charter look like if it were written today? Crit Public Health 18(4):435-441

Ottawa Charter for Health Promotion (1986) Health Promot Int 1:405. https://doi.org/10.1093/heapro/1.4.405

Ottawa Conference Report (1986b) Creating environments conducive to health. Health Promot Int 1:453-457. https://doi.org/10.1093/ heapro/1.4.453

Ottawa Conference Report (1986c) Strengthening communities. Health Promot Int 1:449-451. https://doi.org/10.1093/heapro/1.4.449

Ottawa Conference Report (1986d) Developing personal skills. Health Promot Int 1:457-458. https://doi.org/10.1093/heapro/1.4.457
Ottawa Conference Report (1986e) Reorienting health services. Health Promot Int 1:459-460. https://doi.org/10.1093/heapro/1.4.459

Pettersson B (2011) Some bitter-sweet reflections on the Ottawa Charter commemoration cake: a personal discourse from an Ottawa rocker. Health Promot Int 26(2):):173-):179. https://doi.org/10.1093/ heapro/dar080

Porter C (2007) Ottawa to Bangkok: changing health promotion discourse. Health Promot Int 22(1):72-79. https://doi.org/10.1093/ heapro/dal037

Scriven A, Speller V (2007) Global issues and challenges beyond Ottawa: the way forward. Promot Educ 14(4):194-198

Thompson SR, Watson MC, Tilford S (2017) The Ottawa Charter 30 years on: still an important standard for health promotion. Int $\mathrm{J}$ Health Promot Educ 56(2):73-84. https://doi.org/10.1080/ 14635240.2017.1415765

European Public Health Association, Austrian Society for Public Health (2016) Vienna Declaration. European Public Health Association and Austrian Society for Public Health, Vienna

Weare K, Bunton R, Macdonald G (1992) The contribution of health education to health promotion. In: Bunton R, Mcdonald G (eds) Health promotion: disciplines, diversity and developments. Routledge, London, pp 103-125

World Health Organization (2009) Milestones in health promotion. Statements from global conferences. World Health Organization, Geneva

Wills J, Douglas J (2008) Health promotion: still strong? Crit Public Health 18(4):431-434

Wise M, Nutbeam D (2007) Enabling health systems transformation: what progress has been made in reorienting health services? Promot Educ 14(2):23-27

Ziglio E, Hagard S, Griffiths J (2000) Health promotion development in Europe: achievements and challenges. Health Promot Int 15(2):143154. https://doi.org/10.1093/heapro/15.2.143

Ziglio E, Simpson S, Tsouros A (2011) Health promotion and health systems: some unfinished business. Health Promot Int 26(2):216225. https://doi.org/10.1093/heapro/dar079

Publisher's note Springer Nature remains neutral with regard to jurisdictional claims in published maps and institutional affiliations. 